Artigo

\title{
avaliações externas, escolas, professores de matemática, máquinas de guerra, aparelhos de estado,
}

large scale assessment, schools, mathematics teachers, wars machine, state apparatus, evaluaciones externas, escuelas, profesores de matemáticas, máquinas de guerra, aparatos estatales,

\author{
João Ricardo Viola dos Santos ${ }^{1}$ \\ [0000-0003-4560-4791] \\ Edivagner Souza Santos ${ }^{2}$ \\ [0000-0002-0621-3731]
}

\begin{abstract}
Resumo
Nesta produção inventiva multiplicamos efeitos de avaliações externas em espaços escolares. Nesse movimento, nossas produções flertam em diálogos com alguns escritos de Gilles Deleuze e Felix Guattari, com outros pesquisadores que se inventam em conceitos destes pensadores, com entrevistas com professores de matemática de escolas públicas do Ensino Fundamental. Nessa produção inventiva somos produzidos por afetos que atravessam uma estratégia neoliberal que se esforça em produzir uma escola como uma mercadoria em detrimento a uma escola como direito. Efeitos de avaliações externas são produzidos em pressões e vigilâncias, operados nas escolas em privilégios e supremacias de uma disciplina em função de outra, em situações de adoecimentos de professores, em promessas de melhoria e qualidade da educação, em alunos como números, em...
\end{abstract}

Palavras-chave: Avaliações Externas. Professores de Matemática. Escolas. Filosofias da Diferença.

\begin{abstract}
In this inventive production we multiply the effects of large scale assessment in school spaces. In this movement, our productions flirt in dialogues with some writings by Gilles Deleuze and Felix Guattari, with other researchers who invent themselves in the concepts of these thinkers, with interviews with mathematics teachers from public Elementary schools. In this inventive production we are produced by affections that go through a neoliberal strategy that strives to produce the school as a commodity to the detriment of a school as a right. Effects of large scale assessment are produced in pressures and survilliance operated in schools, in privileges and supremacy of one discipline over another, in situations of illness of teachers, in promises of improvement and quality of education, in students as numbers, in ...
\end{abstract}

Keywords: Large scale assessment. Mathematics Teachers. School. Philosophy of Difference.

\section{Resumen}

En esta producción inventiva, multiplicamos los efectos de las evaluaciones externas en los espacios escolares. En este movimiento, nuestras producciones coquetean en diálogos con algunos escritos de Gilles Deleuze y Felix Guattari, con otros investigadores que se inventan en los conceptos de estos

1 joao.santos@ufms.br, Doutor, Professor, Universidade Federal de Mato Grosso do Sul, Campo Grande/MS/Brasil.

2 vaguinhos.santos@gmail.com, Mestre, Doutorando, Universidade Federal de Mato Grosso do Sul, Campo Grande/MS/Brasil. 
pensadores, con entrevistas a profesores de matemáticas de escuelas primarias públicas. En esta producción inventiva somos producidos por afectos que pasan por una estrategia neoliberal que busca producir una escuela como mercancía en detrimento de una escuela como derecho. Los efectos de las evaluaciones externas se producen en presiones y vigilancias, operadas en las escuelas en privilegios y supremacía de una disciplina sobre otra, en situaciones de enfermedad de los docentes, en promesas de mejoramiento y calidad de la educación, en alumnos como números, en ...

Palabras claves: Evaluaciones externas. Profesores de matemáticas. Escuelas. Filosofías de la diferencia

\section{Sempre: apenas mais uma vírgula}

\section{Você quer saber se meus alunos aprenderam o conteúdo?} Simples: é só perguntar para mim.

Esta é uma afirmação de um colega professor de matemática da Educação Básica, em uma conversa com um técnico da secretária de educação a respeito das avaliações externas, cada vez mais presentes no dia a dia da escola. São inúmeras as problemáticas desdobráveis com essa pergunta desabafo, sobrevivência. Nem sempre as práticas avaliativas movimentadas na escola se constituíram em função de investigar processos de ensinos e aprendizagens, em função de oferecer tomadas de decisões tanto para alunos quanto para professores. Entretanto, atualmente, professores, alunos, diretores, coordenadores elaboram suas ações pedagógicas em função de uma avaliação externa à escola. Pouco se sabe, pouco se discute e se problematiza; é sempre a saga da busca do índice.

Agentes exteriores às escolas produzem instrumentos homogêneos, sob uma lógica de classificação, que carrega um processo de exclusão (mesmo que disfarçado), para dentro de um espaço que é complexo, singular, contingente e que explicita e congrega muitas mazelas e desigualdades de nossa sociedade. Estes instrumentos chegam com uma roupa chique e uma promessa: melhoria da escola na busca de uma educação de qualidade. Esta esperança está no âmago desses instrumentos. Alguns resultados: professores produzem suas aulas em função desses instrumentos, em busca do tão sonhado índice. A aula de matemática, as atividades, os alunos, as dinâmicas são produzidas para alcançar ou manter um bom índice. Avaliações externas se constituem nas escolas como indutores de currículo. Elas funcionam como uma estratégia política e econômica, na manutenção de um modelo de sociedade que acentua desigualdades, sob a narrativa da globalização e do crescimento econômico.

Avaliar, então, pode ser produzido como um ato de resistência em sala de aula, com (e não contra) os atravessamentos que atropelam práticas profissionais de professores. Talvez, um atravessamento poderoso no dia a dia da escola é a temida avaliação externa. Avaliar como resistir engloba e se compõe com avaliar como uma prática de investigação, bem como se constitui como um ato de criação, invenção. Há uma possibilidade em deixar um pouco de lado a esperança e o medo, como afetos que imobilização e deixam, muitas vezes, as coisas como elas estão, pois operam na temporalidade da expectativa, e convida ao desamparo, um afeto que opera na ordem do contingente, daquilo que não se anuncia em um horizonte de possibilidades (SAFATLE, 2015). Como em Viola dos Santos (2020), 
Não há como antecipar o que acontece em salas de aulas de Matemática; daí decorre que não há como antecipar práticas avaliativas que sejam úteis e potencializadoras para o trabalho do professor, útil na direção de servir alguma demanda do professor, de seus alunos e do dia a dia de sua escola. Potencializadoras, no sentido de dar potência, abrangência e amplitude para suas estratégias político-pedagógicas. $O$ afeto do desamparo oferece possibilidade de pensar o avaliar como ato de resistência, pois ele nos impulsiona a construir com aquilo que não sabemos, subvertendo certas lógicas e colocando nossos processos de produção de significados em outros planos de significações (VIOLA DOS SANTOS, 2020, p. 24).

Pois bem, nos inventamos em escritos-experimentações em uma produção na qual multiplicamos (somos multiplicados) efeitos de avaliações externas em espaços escolares. Nesse movimento, nossas produções flertam em diálogos com alguns escritos de Gilles Deleuze e Felix Guattari, com outros pesquisadores que se inventam em conceitos destes pensadores, com entrevistas com professores de matemática de escolas públicas do Ensino Fundamental. Leituras, afetos, lógicas, narrativas, efeitos outros são produzidos. Estes, sempre contingentes, ora cá, ora acolá, ora os dois, no mesmo, também na diferença.

Nossas escrita-experimentações se entrelaçam em discussões com avaliações externas; em escritos com os conceitos de máquina de guerra e aparelho de estado; em resistências; em educações menores; em avaliações menores; em e com falas de professores de matemática sobreviventes, inventivos em escolas.

Sempre: apenas mais uma vírgula ${ }^{3}$.

Esta imagem do artista sueco Tommy Ingberg, mais outra vírgula, talvez se constitua como outro modo de escrita que se coloca em nossas invenções.

São problemáticas como essa que se impõe em nossas salas de aulas: sentimos, sofremos, mas ainda lidamos com um guarda-chuva.

\footnotetext{
${ }^{3}$ Nossas escrita-experimentações foram produzidas em um movimento no qual, efeitos de avaliações externas se multiplicam em forma de parágrafos. Não há de um lado as falas de professores de matemática, de outro nossas discussões com ideias de Gilles Deleuze e Felix Guattari e, ainda, de um outro lado, nossas análises e discussões. Há um movimento, uma produção inventiva na qual, efeitos de avaliações externas são produzidos. Escritos de outros autores e trechos de textualizações de entrevistas com professores de matemática, também em forma de parágrafos, compõem nossa composição, sendo que estes são explicitados com as devidas citações. Nossa invenção é uma aposta em tentar produzir possibilidades outras em escritas acadêmicas outras. Claro, que "de fora" é possível explicitar limitações ou mesmo controvérsias, contradições deste modo de escrita. Nosso convite, então, é olhar "por dentro" (e com esse dentro): que efeitos pode essa escrita-experimentação? Ah, "dentro" e "fora" é também outro deslize, entre tantos, apenas mais um abuso de/em nossa escrita.
} 


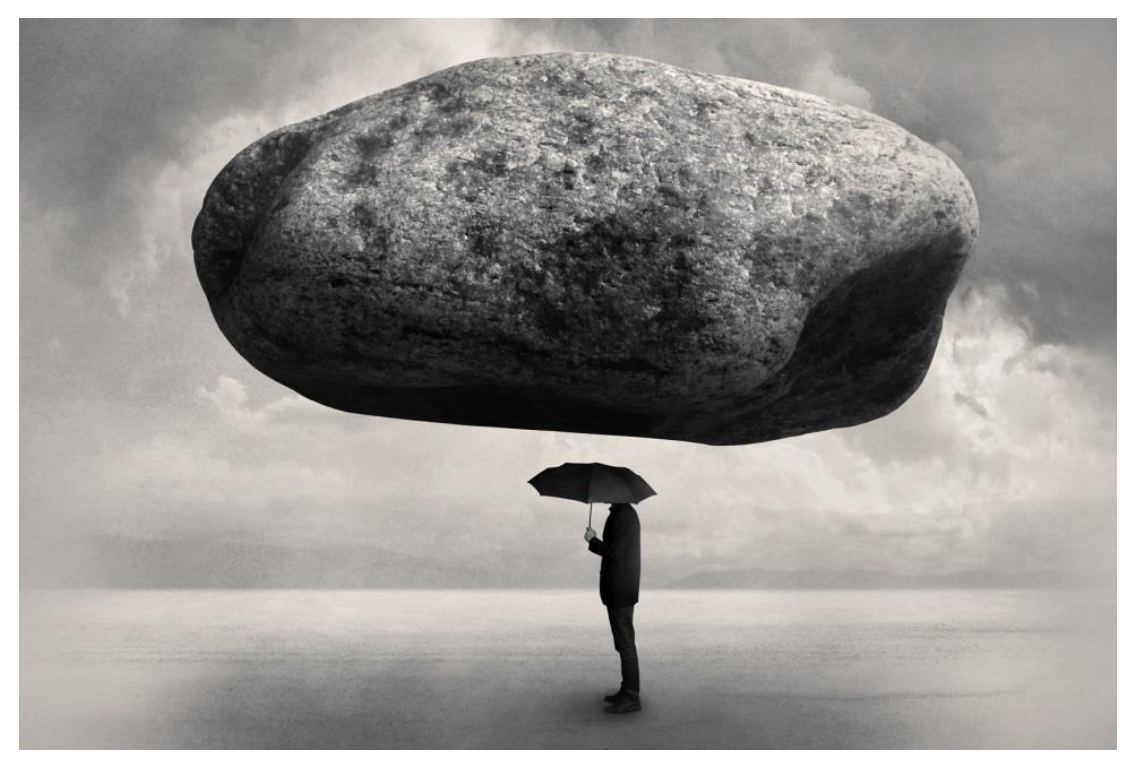

Stone Part 1 - Tommy Ingberg

Fonte: http://ingberg.com/?Page=view artwork\&PID=60\&ImagelD=16

, pois sempre são operadas bandeiras da melhoria, do progresso e também da homogeneização, classificação, exclusão

As frases de efeitos de avaliações externas são interessantes: melhoria da escola; busca de uma qualidade da educação; todos precisam ter as mesmas condições para aprender matemática na escola; é preciso uma mesma métrica para todas as escolas; é necessário ter um sistema nacional de averiguação dos desempenhos dos alunos, um sistema que ofereça as mesmas possibilidades para todos os alunos brasileiros; por meio das avaliações externas os alunos vão aprender cada vez mais...

O sistema de Avaliação de Desempenho Escolar na Rede Municipal de Ensino de Campo Grande/MS (REME) foi instituído em 29 de dezembro de 2005, por meio da Lei $n$. 4.358. Desde então foram realizadas diversas avaliações em diferentes séries/anos da REME. Os usos dos resultados obtidos em uma avaliação são múltiplos, mas seu propósito é a garantia da qualidade. No caso da Secretaria Municipal de Educação de Campo Grande - MS, essa qualidade se reflete na aprendizagem do aluno e passa pela atuação do professor e do programa curricular utilizado. (CAMPO GRANDE, 2011, p.10)

Uma narrativa da homogeneização [todos? Como assim?], atrelada à classificação [escola para classificar?], que implica em exclusões [mas não era contra isso que sempre lutamos?] se institui da maneira perversa nas escolas. Universalidade e igualdade se constituem como grandes narrativas em uma direção de oferecer as mesmas condições para as crianças nas escolas. O Brasil é um país continental, por isso é preciso uma base comum curricular para conhecer todos os nossos alunos. Diante de uma base comum, podemos avaliálos e, por conseguinte, ter uma estratégia para a melhoria da educação. Bingo! Resolvemos um problema da escola. Não podemos esquecer que o culpado é o professor. Muitas vezes eles não têm vontade de produzir mais, de buscar um avanço em suas aulas. Até mesmo porque, se o aluno vai bem ou mal, sua aula é a mesma e seu salário está garantido. Não há problema, pois vamos mexer no bolso deste professor: décimo quarto salário para os professores que atingirem os índices das avaliações externas em suas escolas. Bingo! Resolvemos mais um problema da escola. 
Essa narrativa é perversa, pois ela se institui, se espalha e produz uma escola com a promessa da melhoria. Com isso, uma expectativa de algo que está por vir, imobiliza ações transformadoras em um presente: deixa tudo como está. A perversidade destas narrativas está em violentar os afetos e com isso vontades de agir. É uma situação complexa, por exemplo, problematizar os décimos quartos salários de professores em escolas que atingem os índices: como ir contra e explicitar que essa política como um todo, apenas aprofunda a precarização do trabalho docente?

Muitas vezes, em nossas ações cotidianas, a expectativa de que algo aconteça ocupa muito espaço e inibi, ou mesmo anula, possibilidades de algumas transformações, mesmo que muito restritas e "pequenas". Atingimos o índice; ufa! O que isso significa? Pouco importa, pois este índice explicita um "bom" trabalho aos olhos externos à sala de aula, ao dia a dia do professor com seus alunos. A caminhada a passos de tartaruga em busca do índice, impõe à escola poucas possibilidades. Entretanto, caminhar, mesmo que devagar, oferece um respiro de alívio, de um ano sem pressão, sem vigilância, sem controle...

A servidão voluntária do funcionário de Estado pode ser justificada pelas garantias fornecidas pelas centrais de poder que fazem dos funcionários sujeitos a receberem futuros proventos (bônus) previdenciários. (ZORDAN, 2014, Aforismo 4)

Uma bandeira da melhoria, do avanço, pode ser exemplificada como o seguinte exemplo: Em média no último IDEB, o estado de Mato Grosso do Sul teve o seguinte resultado:

\begin{tabular}{|c|c|}
\hline Nível de Ensino & Média do IDEB \\
\hline Ensino Fundamental I: & 5,6 \\
\hline Ensino Fundamental II: & 4,6 \\
\hline Ensino Médio: & 3,6 \\
\hline
\end{tabular}

Vejam só, está claro: estamos progredindo! O Ensino Fundamental I vai bem, o Ensino Fundamental II, nem tanto. Mas não é ruim. Nosso problema é o Ensino Médio. Sempre o Ensino Médio. Precisamos ainda melhorar e já estamos melhorando! Estamos progredindo! Chegaremos lá.

Efeitos, narrativas, lógicas de avaliações externas servem muitas vezes apenas para deixar tudo como está, porém com uma narrativa da transformação, sob bandeiras da melhoria, do progresso, da busca de um ideal. Onde estão os alunos que passaram por essa escola? Como estão? De que modo construíram suas vidas? Essas são perguntas pouco movimentadas em políticas públicas em relação aos alunos que passam pelas escolas públicas. Essa falta de preocupação, ou mesmo descaso, pode indicar que as escolas apenas sobrevivem e pouco participam de um projeto de estado, e não de governo, no qual em meio a uma comunidade, a escola, um espaço público, dialoga e se inventa com modos de produção econômicas, instâncias culturais, espaços políticos, modos de organização de vidas.

Eu acho que essa relação de mostrar esses números em relação a essa prática social, a avaliação externa não vai mostra. Esses números não mostram essa realidade. Acredito que a Secretaria de Educação não se importa com essa informação. É algo que se fica, e é aqui dentro da escola que é tratado, que tem que ser feito essa conscientização. Agora, de que forma? Nós não sabemos. Nós não sabemos. O que é pensado lá é pensado para as 96 escolas de Campo Grande. Não é pensado para as Escola Municipal Consulesa Margarida Maksoud Trad, para o Irmã Edith Coelho 
Netto, lá para Antonio José Paniago, na minha região. Eu moro naquela região, do lado de lá. Eu não sou daqui dessa região. Ali tem a escola Professora Arlene Marques Almeida, que é bem periferia mesmo, a realidade é outra, é difícil. Vai além do que a gente sabe. Vai muito mais além do que a gente sabe. Então eu acho que em situações de cobrança da Secretaria de Educação, penso eu, que essa cobrança é em cima do que a educação pode fazer em situações ideias. Então, por isso que não levam em conta os fatores. (Professor Afonso)

Essa busca por uniformização/homogeneização se materializa na construção de avaliações e comparações da educação em larga escala, criando um cenário de consolidação de um monstruoso desejo do Estado em garantir seu controle sobre a população (GALLO E MONTEIRO, 2020, p. 191).

O controle é também fabricado, articulado, operado no nível do desejo. A felicidade, o sentimento de dever cumprido de professores quando os resultados positivos de uma avaliação externa de uma escola são divulgados é um exemplo de como o controle do desejo opera.

A preocupação do Estado é conservar (DELEUZE, GUATTARI, 1997, p. 11).

\section{, pois meu trabalho é a Prova Brasil: vigilâncias, pressões, adoecimentos}

Fixar, sedentarizar a força de trabalho, regrar o movimento do fluxo de trabalho, determinar-Ihe canais e condutos, criar corporações no sentido de organismos, e, para o restante, recorrer a uma mão-de-obra forçada, recrutada nos próprios lugares (DELEUZE, GUATTARI, 1997, p. 28)

Até mesmo porque veio material para escola e eles estão dando uma pressão nos professores assim: ó gente, a Prova Brasil do nono ano! Como eu trabalhei mais no laboratório, eu não tive muito esse contato direto. Mas o ano passado ficou bem parado esse negócio da prova. Não tinha isso: vamos preparar pra prova! Vamos preparar pra prova! Esse ano está um tom diferente! Esse ano é um ano ímpar, e ela acontece esse ano. Esse ano está bem puxado esse negócio: vamos trabalhar pra Prova Brasil. E é preparar mesmo. Exercícios e treinamento. Não é o que eu acredito, mas é o que eu tenho que fazer para atender. (Professora Verônica)

Ao mesmo tempo em que a responsabilidade do trabalho em sala de aula é do professor, suas estratégias político-pedagógicas são construídas em direções que, muitas vezes, ele não acredita.

Ao mesmo tempo em que é reconhecido, por vários e diversos profissionais, que cada sala de aula tem sua especificidade e que é preciso ler os alunos em suas singularidades, apostilas, simulados e formações generalizantes e generalizadas atravessam o dia a dia do professor.

A generalização como uma estratégia matemática cada vez mais presente em nossa sociedade, não apenas de procedimentos e algoritmos, mas também de emoções e modos de lidar com demandas sentimentais opera de modo mais pungente na escola.

Avaliações externas muitas vezes funcionam como um braço forte de uma política neoliberal que se instala cada vez mais na escola (um aparelho estado). Salas de aulas, alunos, professores que sobrevivem e resistem como podem (uma máquina de guerra). Efeitos e narrativas de controle se inventam, se misturam, se multiplicam, se interiorizam, se... 
O importante é não cair, então vamos controlar, vamos estar junto com os professores fazendo uma pressão. Não podemos ficar longe, temos que estar com os professores: ano de Prova Brasil é necessário uma pressão maior.

Essas são narrativas de vigilância que atravessam o trabalho de técnicos das secretarias de educação.

Muitas vezes, estes também sabem que pressões em um trabalho pontual, desconsiderando todo o contexto familiar, pouco afetam condições e possibilidades do trabalho em sala de aula. Porém, ele está no jogo e sua função (mais um efeito) é produzir um "acompanhamento", uma "formação particularizada" que se traduz em vigilância, busca e manutenção de resultados. Não se trata de produzir uma identidade para o técnico das secretárias, para os diretores de escolas, para os coordenadores educacionais, apontando-os como agentes do controle, como sujeitos (com uma identidade fixa) que aterrorizam o trabalho dos professores. Eles também são produzidos como efeitos de avaliações externas.

A Prova Brasil mesmo, eu tenho que pedir para os alunos virem. Eu falo: vocês precisam fazer a prova: leem esta prova direito. Aí eu fico botando na cabeça deles que eles precisam vir. E todos eles vêm. Porque eu peço para eles vir. É o respaldo que eles têm. É o respeito! Eu faço meio que um acordo com os alunos, porque a prova não tem sentido para eles nenhum. Eles nem sabem o que é Prova Brasil. O que é uma avaliação dessas. A nossa escola é uma com os maiores índices. Eles nem sabem disso. Nem passa na cabeça deles o que é isso. Mas todos os alunos vêm no dia da prova porque eu peço para eles virem. Tem que vir, por que senão meu nome vai ficar ruim. Eu fico jogando para eles. E eles vêm! (Professora Fernanda)

No caso da resistência dos alunos, houve uma definição de, no dia de aplicação da avaliação na escola, fazerem um teste com a finalidade de produzirem um resultado não satisfatório à escola. Dessa forma, demonstraram o quanto a situação de atender a uma demanda que não era específica do grupo os afetava. A decisão em fazer o teste para produzir um resultado que os outros não queriam caracteriza, além de resistência, a afirmação de seus espaços, de suas diferenças. Eles negam a imposição de uma avaliação externa, por meio da resistência, ou seja, produzindo um resultado pelo qual explicitam a insatisfação em serem responsabilizados pelo alto ou baixo IDEB, uma vez que esse resultado não os fortalece. Tratase de uma isenção de culpa a priori por uma situação que, definitivamente, não tinha sido produzida por eles. Assim, a turma de nono ano limitou o caráter invasivo dos testes ao intervir negativamente na produção de determinado resultado e não tomou para si o peso daquilo que não foi construído "com" eles. Desse modo, houve reação pela resistência ao processo homogeneizador da avaliação em larga escala. (GOMES, 201, p. 144-145).

Vigilância, pressão são efeitos produzidos que se multiplicam nos espaços: secretária da educação sobre alunos; coordenador sobre diretor; professor sobre aluno; aluno sobre diretor de escola; prefeito sobre professor; pai de aluno sobre o prefeito... Não há uma origem ou implicações descendentes (do mais poderoso, para o menos poderoso), nem mesmo ascendentes. Vigilâncias, pressões apenas se multiplicam.

Este ano, este mês agora, foi tão forte a intervenção lá que a coordenadora vai até pegar licença. Porque tão forte veio em cima dela. Parece que já veio de lá que a escola é boa, que não sei o que, mas que você tem que fazer isso, isso e isso. Então o próprio coordenador, se ele não souber... se ele carregar isso para casa dele as coisas que estão 
na escola, ele fica doente. Tanto o coordenador [comparando com o professor], porque o coordenador também sofre esta intervenção. Ela é minha coordenadora, ela me acompanha, então ela e eu que vamos sofrer esta intervenção. Ela não está bem, vai sair de licença de tanta coisa da intervenção, porque ela está sofrendo intervenção de português. (Professora Fernanda).

Porque a SEMED faz os atendimentos com a gente. Vêm os técnicos de matemática, sentam, quase todo bimestre, ou pelo menos uma vez no semestre. Às vezes eles vêm, traz uma atividade, traz uma proposta diferente de algum conteúdo. Outras vezes eles vêm mais para avaliar mesmo o que estamos fazendo, para olhar nosso caderno de planejamento como se fosse vistoriar nosso trabalho. Com certeza a gente sofre pressão. Eu não consigo pensar assim: teria como não sofrer? Acredito que não, porque o tempo todo a gente está sendo avaliado. E essas provas que vem, seja da SEMED, seja a Prova Brasil ou uma OBMEP, elas não avaliam só os alunos. Elas avaliam o professor. E principalmente o professor. Porque se uma turma toda vai ruim, eles não vão olhar pra aquilo considerando que os alunos não sabem. Não, eles vão olhar para aquilo e falar assim: poxa, vamos fazer alguma coisa com esse professor. (Professora Verônica)

Outro benefício do sistema de avaliação foi a possibilidade de consentimento de uma "autonomia vigiada" às escolas, já que as unidades escolares têm assegurado o controle das ações diante dos seus resultados (CAMPO GRANDE, 2011, p. 16).

Os resultados controlam as ações, são mecanismos de vigilância e autovigilância; sem consentimento do lado de cá; a perícia proposta pelos testes define a possibilidade, o propósito, e quem se responsabilizará pelos resultados. O mote é o controle das ações! O foco é a Prova Brasil! A máquina que produz dados, que faz sujeitos maquinados, tratados, normalizados, sujeitados...

Distinguimos como dois conceitos a servidão maquínica e a sujeição social. Há servidão quando os próprios homens são peças constituintes de uma máquina, que eles compõem entre si e com outras coisas (animais, ferramentas), sob o controle e a direção de uma unidade superior. Mas há sujeição quando a unidade superior constitui o homem como um sujeito que se reporta a um objeto tornado exterior, seja esse objeto um animal, uma ferramenta ou mesmo uma máquina: o homem, então, não é mais componente da máquina, mas trabalhador, usuário..., ele é sujeitado à máquina, e não mais submetido pela máquina (DELEUZE, GUATTARI, 1997, p. 137).

Uma escola que, muitas vezes, se resume em fazer com que seus alunos tenham um bom desempenho na Prova Brasil, estreita possibilidades da produção de humanidades outras; de éticas outras; de construções de espaços inventivos nos quais criatividades, responsabilidades outras sejam produzidas; de produções de leituras das lógicas e narrativas coloniais que atravessam as relações em nossa cultura (sejam entre humanos e nãohumanos); da produção de lógicas e narrativas outras que não busquem o ideal do estado de bem estar europeu (vamos ser no futuro uma nação de primeiro mundo; se nossas escolas fossem como as da Finlândia, logo...).

Vigilâncias, pressões, adoecimentos se multiplicam.

Uma escola produzida em adoecimentos precisa ser posta em suspensão. 
Talvez, não se trata de identificar problemas para resolvê-los, pois a problemática é estrutural ao nosso modo de produzir esses problemas. Estes, muitas vezes são sintomas de nossas relações entre humanos e não-humanos. Nossas invenções vidas, fincadas em binaridades (homem/mulher; preto/branco; alto/baixo, entre tantas outras, tão ingênuas e tão perversas ao mesmo tempo), na supremacia entre espécies, na ideia de progresso e desenvolvimento econômico, se constituem como demandas. Neste ano, 2020, um exemplo exemplar seria a Covid-19. Não trata de um problema sanitário, mas sim de um sintoma da relação entre humanos e não-humanos.

Uma ideia de escola centrada em construir estratégias de aprendizagens para alunos pode ser um estreitamento, pois junto com aqueles que aprendem estão aqueles que, por ventura, não aprendem. Com isso, outra dicotomia se instaura e, por conseguinte, uma ideia do fracassado, do excluído. Outra ideia de escola pode ser inventada em composições com um conceito de pertencimento, de compromissos. Escola como um espaço de construção e manutenção de compromissos, em uma estrutura relacional do pertencer. Compromissos com o dia a dia, com invenção de projetos; compromissos com ideias outras que quero construir com meus colegas.

Apenas outro talvez, de uma escola outra.

\section{a impressora da escola é praticamente minha, nos conselhos de classe, minha decisão muitas vezes prevalece}

E sobre a matemática? Ora, esta é o carro chefe da escola na busca do índice. 0 português também. São esses dois professores que sempre explicitam um efeito de soberania na escola. Em um espaço constituído sob a lógica das avaliações externas, professores de matemática e de português operam como reguladores do que pode, não pode, deve ou não deve ser feito. Concordar ou não, se isso é certo ou errado, pouco importa. No dia a dia, sempre acelerado das escolas, muitas vezes, isso se torna naturalizado. Sempre foi assim, não há o que fazer. Se um aluno não vai bem, em História ou Educação Física, não há problema, pois ele tirou um notão em matemática.

A forma-Estado, como forma de interioridade, tem uma tendência a reproduzir-se, idêntica a si através de suas variações, facilmente reconhecível nos limites de seus pólos, buscando sempre o reconhecimento público (o Estado não se oculta). (DELEUZE, GUATTARI, 1997, p. 18).

O peso da matemática especificamente naquela escola é muito alto. É muito cobrado. E o professor de Matemática tem um poder de voz maior que os outros. [...] Agora voltando ao assunto, porque eu acho que o professor de matemática tem um tom de voz a mais do que os outros. Não concordo, mas eu acho que tem dentro da escola. Por exemplo, algo que acontece muito é assim, toda escola tem o conselho de classe, todo final de bimestre tem o conselho de classe, e aí eu percebo às vezes, por exemplo, se o professor de Artes fala uma nota ruim de um aluno: o aluno tirou quatro. $O$ outro professor de Educação Física: ele tirou quatro. Aí eles perguntam: a matemática tirou quanto? Tirou oito. Ah não, vamos ver se a gente consegue mudar nossa nota? Porque assim, se em matemática o garoto tirou oito a gente vai dar quatro, vai dá três? Vai dar nota baixa em Educação física? Hum... Artes? Como se não tivesse uma importância. Eu não sou professora de Educação física, eu não sou professora de Artes, mas eu me sinto assim. Não é legal fazer isso com o outro professor. Porque se 
eu fosse professor dessas disciplinas falaria assim: não, ele tirou isso mesmo e vai ficar com nota baixa. Não importa, porque não vai importar pra mim se ele tirou nota alta em matemática. Esse aluno gênio que eu tenho, por exemplo, só tira dez em matemática, mas é horrível em outras disciplinas, e nem por isso a gente tem que passar a mão na cabeça. E eles sempre perguntam. Eu acho que esse peso é sempre para Matemática e Português. Como se fosse assim: o que é importante para um ser humano saber, para se formar de fato um cidadão? Matemática e Português. É isso! Então professor de Português, como que foi? E o de matemática? Então tá tudo certo. Tirou nota em Matemática e Português então está tudo certo. Vamos tentar mudar estas coisas? Agora tirou uma nota alta em outras disciplinas e não tirou em Português e Matemática, aí fica aquela coisa: então vamos deixar para semestre que vem, porque a gente aplica outra avaliação. Nisso eu percebo. Eu percebo muito! (Professora Verônica).

A lei do Estado não é a do Tudo ou Nada (sociedades com Estado ou sociedades contra o Estado), mas a do interior e do exterior. O Estado é a soberania. No entanto, a soberania só reina sobre aquilo que ela é capaz de interiorizar, de apropriar-se localmente (DELEUZE, GUATTARI, 1997, p. 18). /.../ O aparelho de Estado não tem uma máquina de guerra, ele tão somente se apropria de uma na medida em que é principalmente uma potência de apropriação ou um aparelho de captura (FERREIRA, p. 110, 2014).

As disciplinas de português e matemática são as principais! Tem um peso maior! O que vem para avaliar às outras só pegam uma carona. Os que já são cobrados mesmo. (Professor Afonso)

E são alunos mesmo? São os alunos que importam em salas de aulas atravessadas pelas avaliações externas? Mesmo com o foco em Matemática e em Português, os alunos e seus processos singulares têm atenção em meio às estratégias político-pedagógicas? Por exemplo, há uma preocupação e um trabalho com o aluno João Victor que adora Judô e que gosta de matemática; com o Francisco que gosta de fazer tudo muito rápido e que tem preferência por matemática; com o Cláudio que adora inventar novos mundos, em seus processos criativos; com a aluna Ana que é detalista, caprichosa e muito focada em fazer de maneira bem feita? Com a aluna Maíra que desde os sete anos se dedica à música? Ou o que importa são seus resultados nas avaliações? São os alunos ou o resultado dos alunos?

Faz pouco tempo que entrei nessa escola, eu estava em outra escola no bairro Novos Estados. E essa sondagem foi feita por nós. Usamos até o Google Drive aqui para trabalhar. Com as questões de 2015, inclusive. Nós pegamos as questões de 2015, todas elas, de português e matemática. Os professores ficaram trabalhando essas questões. E jogamos essa prova no Google Drive para os alunos virem aqui, e eles fizeram no individual. Aí foi apresentado o resultado. Em cima desse resultado nós fizemos uma abordagem diferente com os alunos. Apresentamos as questões que tiveram mais erros a esses alunos. Fortalecendo principalmente com relação aos conteúdos que ainda ficavam com dificuldade muito grande. Então trabalhamos em cima dessas questões para que cheguem na Prova Brasil um pouco mais orientado. Quando aplicamos as questões e fazemos o levantamento, ela não vem por aluno específico. Para o que nós fazemos aqui não é preciso. $O$ intuito era conhecer as dificuldades dos alunos, e não saber qual é o aluno que está com dificuldade. Entenda 
por este jeito. Esse foi o nosso modo. Nós fizemos antecipando uma preparação para aquela prova, naquela data, naquele ano. (Professor Afonso).

Há um processo de destituição de singularidades de seres humanos que habitam a escola: alunos deixam de ser alunos e passam a ser números. Nesse movimento, a escola, como uma possibilidade de inventar vidas e narrativas outras na sociedade, se constitui, de maneira contrária, como um espaço de manutenção e aprofundamento de uma sociedade desigual; de preconceitos estruturais, como o racismo e a homofobia; como um aparelho de estado que faz uma manutenção de ritos, mitos.

A Educação maior em que as questões de ordem são o cumprimento de programas e obtenção de um bom lugar no ranqueamento das avaliações de larga escala. O modelo escolar neoliberal nos remete a uma conduta protocolar que nos torna insensíveis, pois somos cobrados exaustivamente pela execução do que foi programado (GALLO E MONTEIRO, 2020, p. 195).

Aparelhado, o sujeito do Estado [talvez o professor em um momento?], mesmo no exercício da cidadania, não se posiciona em prol da vitalidade de seu corpo individual ou coletivo. Corpo de combate a resistir nas ímpias intempéries do território. Esse sujeito vive pelas significações atribuídas a seu próprio papel dentro do Estado. (ZORDAN, 2014, Aforismo 4).

No ano de aplicação e na série. Inclusive nos anos que não tem prova você não consegue xerox para nada lá. Se você precisar de um xerox, você não tem. No ano que tem a prova, você tem xerox, tem tudo. Você tem que fazer toda semana um simulado. Aí o xerox da escola fica só para português e matemática. Não para os outros professores. Quem está fora dos nonos e dos quintos fica sem xerox. A gente quem usa a cota da escola. Entendeu? Eles direcionam mesmo. Eles vão treinar mesmo os alunos lá (Professora Fernanda).

\section{educações menores, avaliações externas menores,}

Trata-se de criar, resistir com isso: avaliações externas, pressões, vigilâncias, adoecimentos; também com sorrisos, alegrias, sonhos... Os tentáculos de um capitalismo contemporâneo que atravessam a escola que habitamos, estão cada vez mais alinhados em uma formação de alunos para o mercado de trabalho, para empreender, para inovar: não é de se estranhar que até mesmo na Universidade, os coaches flertam com uma possibilidade para formação de professores, técnicos, alunos...

Grandes empresas privadas, grandes fundos de investimentos em mercados de ações se aproximam cada vez mais das escolas públicas. É um mercado a ser explorado. Em um capitalismo de plataforma no qual transações, humanos e não-humanos se constituem apenas como números e, por assim ser, descartáveis; a escola é um espaço necessário para manutenção e aprofundamentos de lógicas e narrativas deste sistema ético-filosóficocultural-econômico. Já há poucos espaços para os desempregados: o conceito de ininpregáveis está cada vez mais presente.

É com essas discussões que as salas de aulas de matemática se compõem em nossa contemporaneidade. Não estão fora dos muros da escola, não estão externas às escolas. Assim, essas discussões precisam ser colocadas em movimentos de produzir problemas outros. Funções, Logaritmos, proporções precisam ser produzidos, problematizados com essas demandas econômicas. Invenções outras são necessárias. 
A ideia de aprender e ensinar matemática, muitas vezes constituída de maneira ingênua em nossas escolas e em nossas pesquisas, é atravessada por interesses econômicos que, em última instancia, relacionam-se em decisões sobre aqueles que sobrevivem e aqueles que não. A crise mundial de refugiados é outro exemplo exemplar de nossas produções inventivas.

A solução que vem do meio estatal/empresarial tem sido garantir propostas curriculares homogêneas, com o uso de apostilas, propostas de metodologias ativas (em que os estudantes assumem um papel mais efetivo na gestão da própria aprendizagem), a valorização da meritocracia visando destacar os talentos para que as escolas possam investir nesses alunos de modo a garantir melhores índices nas avaliações. Nesse sentido, a avaliação em larga escala faz parte de um conjunto de elementos que tendem a esvaziar o sentido social e político que alguns tentam defender para a escola. (GALLO E MONTEIRO, p. 191, 2020)

Não se trata de identificar um inimigo, produzir estratégias para derrotá-lo. As avaliações externas se constituiriam assim como o grande inimigo da escola. Essa seria mais uma ingenuidade. Não podemos esquecer que a queda de um suposto inimigo apenas abre possibilidade para o surgimento de outro. Ao invés de identificar, talvez relacionar-se. Ao invés de resolver, talvez produzir problemas outros. Ao invés de colocar um ponto final, talvez outra vírgula. Multiplicar-se; multiplicar-se; fazer rizomas; produzir conexões;

Processos que explicitam lógicas e narrativas de efeitos de avaliações externas nas escolas; espaços nos quais conversas, diálogos, desabafos, confortos e possibilidade de existir com demandas, problemáticas e realizações que acontecem em salas de aula. Nesses espaços, professores, alunos, pais talvez possam se inventarem em escolas outras.

Uma possibilidade, e não a solução, são criações, resistências em avaliações externas menores, educações menores.

As máquinas de guerra, invenções nômades, funcionam como dispositivos que circulam fora das cidades muradas que configuram os Aparelhos de Estado. Seu traçado espiralado, desenha uma linha ziguezagueante, turbilhonar, que vai contra as coordenadas quadrangulares de uma geometria ideal, reguladora, regradora, Régia. A máquina de guerra age zerando coordenadas (retas) e criando números que mostram, aritmeticamente, a progressão errática pela qual as tribos se movimentam (ZORDAN, 2014, Aforismo 0).

Uma educação menor é um ato de revolta e de resistência. Revolta contra os fluxos instituídos, resistência às políticas impostas; sala de aula como trincheira, como a toca do rato, o buraco do cão. Sala de aula como espaço a partir do qual traçamos nossas estratégias, estabelecemos nossa militância, produzindo um presente e um futuro aquém ou para além de qualquer política educacional. Uma educação menor é um ato de singularização e de militância (GALLO, 2002, p. 173).

A educação menor investe na potência, não na instituição de um poder. Fazer fraquejar o sistema pela potência da criação do novo, pela proliferação das diferenças, pela ação de cada professor que, em seu local de trabalho, construindo ou não alianças com outros colegas, consegue aliançar estudantes para um projeto coletivo de aprendizagens inventivas, para projetos coletivos de outros fazeres escolares. Isso muda as cores da escola. Isso produz escolas outras, ainda que continuemos a ver, no macro, a escola instituída de sempre. Mas, nas micro relações, o panorama muda totalmente e outros efeitos serão desencadeados (GALLO, MONTEIRO, p. 197, 2020).

O Estado não pára de produzir e reproduzir círculos ideais, mas é preciso uma máquina de guerra para fazer um redondo (DELEUZE, GUATTARI, 1997, p. 27). 
A Secretaria Municipal de Educação de Campo Grande, acompanhando o contexto de desenvolvimento acima exposto, vem, desde 1999, pelos sistemas de avaliação, incorporando elementos importantes da cultura escolar e busca demonstrar aos professores que a avaliação externa é feita a seu favor, e não contra. Quando a avaliação tem essa conotação, sem dúvida contribui para reafirmar ao magistério a sua dignidade profissional. (CAMPO GRANDE, 2011, p. 24).

Coletivos de professores criam e resistem às estratégias políticas na direção de adestrar seus trabalhos e fazer de seus alunos meros números para o Banco Mundial. Militância, subversões se fazem presentes em ações múltiplas em tentativas de existir de maneiras outras nas escolas. Professores criativamente se inventam em movimentos como estes; possibilidades, desenhos, contornos, fronteiras outras acontecem com essas escolas.

E quando você coloca tudo isso em consideração começa a entender o aluno, que cai o rendimento porque ele está preocupado com a briga em casa, com a confusão em casa, com a falta de alimento em casa, água que não foi paga, a luz não foi paga, tudo isso importa. Aí você vê que ele não tem nem mesa para estudar. Um aluno disse pra mim: eu não tenho mesa pra fazer. Faz no colo ou em cima do local onde deita pra dormir. Como você vai cobrar a alta dessa cara? (Professor Afonso)

Os discursos dos gestores e dos professores, as ações dribladoras das exigências da Secretaria de Educação, a ausência dos alunos em dia de testes, ou ainda, a intencionalidade de uma turma toda em ir mal no teste aplicado, são micropolíticas (BALL, 2006), ou seja, são ressignificações daquilo que querem e não querem para seus espaços, para seus contextos socioculturais. O poder é emanado desses microespaços, exatamente por práticas que contestam a nota do alto IDEB e o disciplinamento voltado ao treinamento para os testes. Nas falas apresentadas, os gestores, ao mesmo tempo em que consideram que a preparação e o disciplinamento são contributos para o alto IDEB, apresentam as dificuldades na manutenção desses pela latência das resistências que emanam desses espaços. Essas resistências foram flagradas nas ações dos alunos que não fizeram a prova, da professora que não deu aula para a prova Brasil, da indiferença da família à faixa fixada na entrada da escola e que sinalizava o posicionamento da escola no ranking. (GOMES, 2019, p. 200)

Em meu município há uma avaliação externa realizada de 3 em 3 anos. Temos entrevistas com os alunos, com os pais, com professores e todos profissionais que trabalham nas escolas. Temos discussões de aulas que são gravadas durante esses períodos. É bem interessante: nós sentamos e nos debruçamos em ler e produzir outras possibilidades para nosso trabalho, tendo como referência nossas aulas. Sempre explicitamos que essa avaliação tem como intenção investigar o sistema. Isso é de extrema importância para nosso trabalho.

Eu soube que no município vizinho é de 4 em 4 anos. Eles fazem outras coisas, bem interessantes também. Talvez, a gente possa olhar como eles fazem e tentar ver nosso contexto. Talvez interesse, talvez não.

Na minha escola nem temos essa ideia de avaliações externas, pois acreditamos que olhares exteriores não se constituem interessantes para nossas estratégias políticopedagógicas. Acreditamos que o dinheiro que gastaríamos com essas avaliações, pode ser empregado em mais professores e um relacionamento mais personalizado com nossos alunos. Nossos esforços são em rodas de conservas sobre/com instrumentos e práticas avaliativas, em partilhar e conhecer outras estratégias em aglutinar os alunos a construírem conosco avaliações outras. 
No estado em que meu primo mora há uma avaliação externa que não lista e nem identifica escolas, professores e alunos. Lá o que interessa é uma leitura das escolas como um todo. Não faz sentido identificar escolas, professores e alunos, pois não há uma intenção de buscar culpados. Há um movimento de pensar estruturalmente o sistema escolar no estado, partilhando fotografias externas, com demandas que acontecem em salas de aulas de escolas. É interessante, pois esses indicativos são incorporados aos projetos de cada escola. Eles ajudam nas discussões e planejamentos de longo prazo que são feitos com a comunidade como um todo.

Talvez, uma ideia seja essa mesma: produzir muitas e diferentes avaliações externas. Multiplicar, multiplicar...

O que temos atualmente, aquilo com que lidamos, são escolas que "vão bem" e outras que "não vão bem" em avaliações externas. Não entrando no mérito do que significa "ir bem", essas últimas escolas, talvez operem como resistências nesse sistema aparelho de estado. Olhar para as escolas que "não vão bem" pode ser interessante, pois talvez essas possam produzir lógicas e narrativas outras. Esta seria uma estratégia interessante nos espaços pesquisas.

Fazer a educação menor como máquina de guerra, não como aparelho de Estado (GALLO, 2002, p. 176).

Fazer avaliações como máquina de guerra, não como aparelho de Estado.

Somos produzidos em afetos que atravessam uma estratégia neoliberal que se esforça em produzir uma escola como uma mercadoria em detrimento a uma escola como direito. Essa demarcação, essa narrativa, está em todo momento passando na frente de nossos olhos e ainda damos pouca importância e valor para criar e resistir com isso.

Talvez, essa é uma grande demanda que precisamos lidar de maneira mais detalhada, articulando elementos econômicos, políticos, éticos. Uma educação como direito se relaciona como um modo de organizar vidas no qual humanos se constituem como humanos, não como números, não descartáveis, em espaços que se constituem democraticamente. Uma educação como direito oferece uma possibilidade de que todos façam parte da construção de projetos políticos, sejam esses quais forem, pautados em uma ética a ser constituída e não em uma moral já cristalizada.

Máquinas de guerra se constituem contra os aparelhos que se apropriam da máquina, e que fazem da guerra sua ocupação e seu objeto: elas exaltam conexões em face da grande conjunção dos aparelhos de captura ou de dominação (DELEUZE, GUATTARI, 1997, p. 96).

Ah, mais uma vez e sempre: apenas mais uma vírgula. 


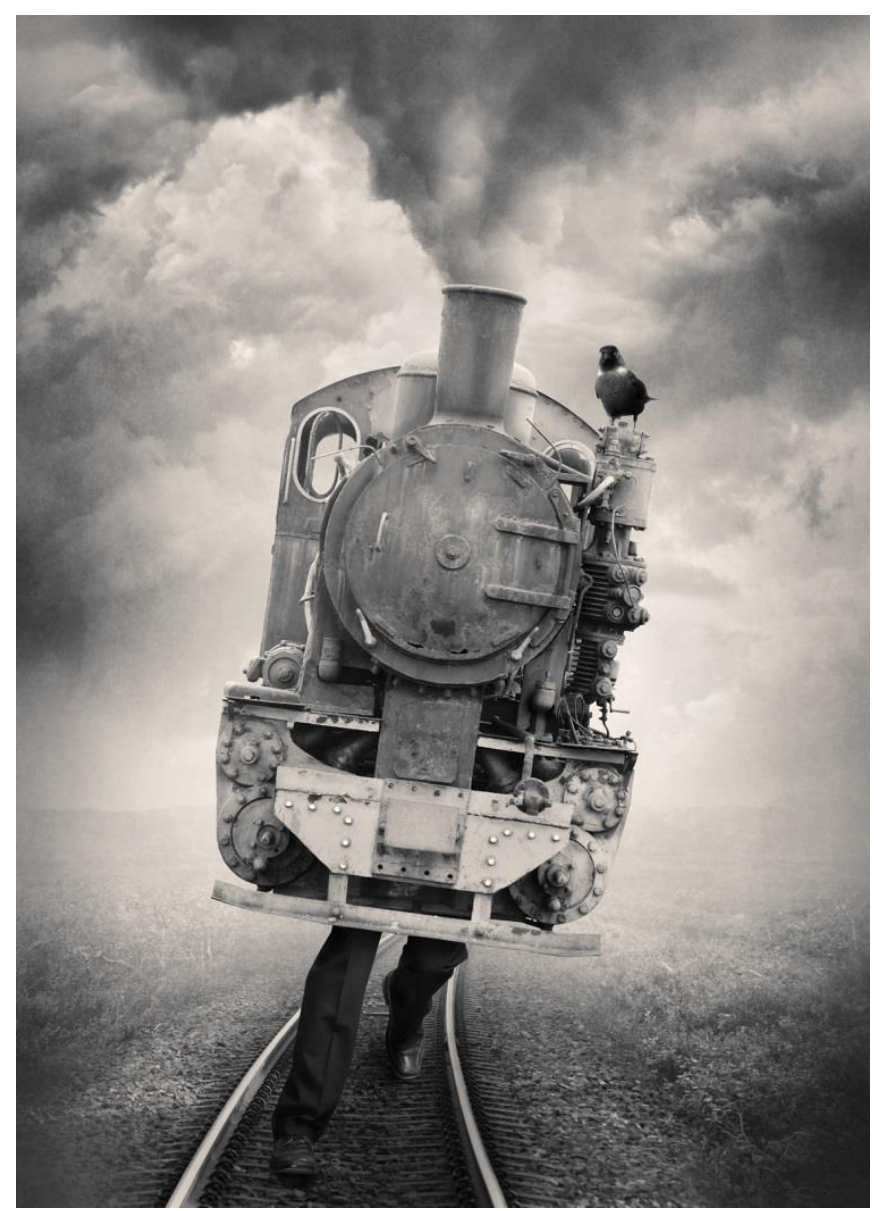

Move - Tommy Ingberg

Fonte: $\underline{\text { http://ingberg.com/?Page=view artwork\&PID=60\&ImagelD=19 }}$

Nesta fotografia, outra vez com Tommy Ingberg em mais uma vírgula, compomos: trata-se de produzir com, não aquém, não além; de inventar com trilhos, amarras, controles, corridas, pássaros, entortamentos...

\section{Referências}

CAMPO GRANDE. Promover educação de qualidade: programa municipal de avaliação externa de desempenho dos alunos da Rede Municipal de Ensino de Campo Grande - MS. Soraya Regina de Hungria Cruz, Marcia Regina Teixeira Mortari Végas, Maria Elisabete Cavalcante (Org.). SEMED, Campo Grande - MS, 2011.

DELEUZE, G; GUATTARI, F. Mil Platôs. São Paulo: Editora 34, 1997. V. 5

FERREIRA, J. P. G. A EXTERIORIDADE DA MÁQUINA DE GUERRA EM MIL PLATÔS: UMA QUESTÃO DE MÉTODO. Kínesis. v. XI, p.133-151, 2019.

GALLO, S. Em torno de uma Educação Menor. Educação e Realidade. V. 27, p. 169-178, 2002.

GALLO, S.; MONTEIRO, A. . Educação menor como dispositivo potencializador de uma escola outra. REMATEC., v. 15, p. 185-200, 2020. 
GOMES, Cladair Martins. Currículo e a Avaliações em larga escala: os gestores de escolas com alto Índice de Desenvolvimento da Educação Básica IDEB. 2019. 215p. Tese (Doutorado em Educação) Universidade Católica Dom Bosco. Campo Grande - MS.

SAFATLE, V. P. O circuito dos afetos: corpos políticos, desamparo e o fim do indivíduo. São Paulo: Cosac \& Naify, 2015.

VIOLA DOS SANTOS, J. R. Entre medos, esperanças e desamparos: possibilidades de resistências para práticas avaliativas de professores de matemática. In: Avaliação e educação matemática: pesquisas e delineamentos. (Orgs) ORTIGÃO, M. I. R.; VIOLA DOS SANTOS, J. R. Brasília: SBEM, 2020.

ZORDAN, P. MÁQUINA DE GUERRA EM DEZ AFORISMOS. Carbono. Dossiê temático. p. 1-17, 2014. 